\title{
Efeito antimicrobiano e sinergístico de óleos essenciais sobre bactérias contaminantes de alimentos
}

\author{
Joseane Cristina Pinheiro Pombo ${ }^{1}$, Evelin Rodrigues Ribeiro ${ }^{2}$, Roberto de Lima Pinto ${ }^{3}$, Bruno \\ José Martins da Silva ${ }^{4}$
}

Os óleos essenciais extraídos de plantas apresentam atividade antimicrobiana frente a diversos microrganismos, e são considerados como alternativa a conservação de alimentos. Este estudo testou o efeito antimicrobiano e sinergístico dos óleos essenciais de Eugenia caryophyllata (cravo) e Origanum vulgare (orégano) sobre bactérias contaminantes de alimentos: Escherichia coli, Salmonella entérica, Staphylococcus aureus e Bacillus cereus. O efeito antibacteriano de diferentes concentrações dos óleos essenciais, puros e em combinação, foi determinado pela técnica de difusão em ágar. O aumento da concentração de óleo essencial provocou um aumento significativo no efeito antimicrobiano $(p \leq 0,05)$. As bactérias Grampositivas foram mais sensíveis aos óleos essenciais, do que as Gram-negativas. O óleo de orégano apresentou um espectro de ação maior em relação ao cravo. As misturas binárias desses óleos na mesma proporção não apresentaram sinergismo. Enquanto as misturas nas maiores concentrações de orégano e menores de cravo apresentaram sinergismo e seu efeito antibacteriano foi potencializado.

Palavras-chave: Óleos essenciais. Sinergismo. Atividade antimicrobiana.

\section{Antimicrobial and synergistic effect of essential oils on food contaminating bactéria}

Essential oils extracted from plants have antimicrobial activity against different microorganisms, and are considered as an alternative to food preservation. This study tested the antimicrobial and synergistic effect of the essential oils of Eugenia caryophyllata (clove) and Origanum vulgare (oregano) on contaminating food bacteria: Escherichia coli, Salmonella enteric, Staphylococcus aureus and Bacillus cereus. The antibacterial effect of different concentrations of the essential oils, pure and in combination was determined by the agar diffusion technique. The increase of the essential oil concentration caused a significant increase in the antimicrobial effect $(p \leq 0.05)$. Gram-positive bacteria were more sensitive to essential oils than Gram-negative bacteria. Oregano oil had a higher action spectrum compared to clove. The binary mixtures of these oils in the same proportion did not show synergism, while the mixtures in the higher concentrations of oregano and lower of clove showed synergism and its antibacterial effect was potentiated.

Keywords: Essential oils. Synergism. Antimicrobial activity

\footnotetext{
1 Programa de Pós-Graduação em Microbiologia da Escola Superior da Amazônia (ESAMAZ). Belém, Pará, Brasi. E-mail: pombojcp@gmail.com.

2 Programa de Pós-Graduação em Microbiologia da Escola Superior da Amazônia (ESAMAZ). Belém, Pará, Brasi. E-mail: ribeiro-evelin@hotmail.com.br.

${ }_{3}^{3}$ Programa de Pós-Graduação em Microbiologia da Escola Superior da Amazônia (ESAMAZ). Belém, Pará, Brasi. E-mail: limaroberto597@gmail.com.

${ }^{4}$ Programa de Pós-Graduação em Microbiologia da Escola Superior da Amazônia (ESAMAZ). Universidade da Amazônia (UNAMA), Ananindeua, Pará, Brasi.

E-mail: bj9611@gmail.com. Endereço para correspondência: Rua Arcipreste Manoel Teodoro, 820 - Batista Campos, Belém - PA, 66015-040. Tel: (91) 98254-4046.
} 


\section{INTRODUÇÃO}

O óleo essencial (OE) se origina do metabolismo secundário das plantas, sendo extraído de flores, botões, folhas, ramos, cascas, sementes, frutos, raízes e rizomas ${ }^{[1]}$. Apresentam compostos aromáticos voláteis como terpenos e seus derivados (carvacrol, timol, eugenol, terpineno, linalol e carvona), que são os principais responsáveis por sua atividade antimicrobiana ${ }^{[2]}$. Estes compostos são capazes de interagir em diferentes moléculas alvo e nas funções das células bacterianas como mecanismos antibacterianos principalmente de inibição da síntese de ácido nucléico, distúrbios nas propriedades da membrana citoplasmática e no metabolismo energético $^{[3]}$.

Várias plantas são utilizadas para extração de $\mathrm{OE}$ tais como: Origanum vulgare (orégano), Eugenia caryophyllata (cravo), Thymus vulgaris (tomilho), Mentha piperita (hortelã), Cuminum cyminum (cominho), Cinnamomum zeylanicum (Canela), Ocimum basilicum (manjericão), Zingiber officinale (gengibre), Rosmarinus officinalis (alecrim), Cymbopogon nardus (citronela) Coriandrum sativum (coentro), entre outras ${ }^{[4,5]}$. A combinação destes óleos de diferentes espécies de plantas pode representar alternativa para potencializar a ação dos mesmos, criando um sinergismo, uma interação positiva em que dois ou mais agentes em combinação exercem efeito inibitório maior que cada agente isolado ${ }^{[6,7]}$.

Dentre os óleos com propriedades antimicrobianas, destacam-se o cravo, que é uma espécie pertencente à família Myrtaceae e possui como principal constituinte o eugenol e baixos teores de acetato de eugenila e $\beta$ cariofileno $^{[8,9]}$; bem como o orégano, pertencente à família Lamiaceae, que apresenta como componentes majoritários o carvacrol e o timol e como componentes minoritários alcoóis monoterpênicos (linalool, 4-terpineol), hidrocarbonetos monoterpênicos ( $p$-cimeno, terpinoleno, terpineno e pineno) e sesquiterpenos ( $\beta$-cariofileno, germacreno $\mathrm{e}$ espatulenol) ${ }^{[10]}$.

O uso de OE como agente antimicrobiano natural em produtos alimentícios pode ser uma alternativa para aumentar a segurança e a vida de prateleira dos alimentos ${ }^{[2]}$. Uma vez que, os microrganismos são os principais responsáveis por Doenças Transmitidas por Alimentos (DTA). A ingestão de água e alimentos contaminados por patógenos vivos ou suas toxinas podem causar infecções, intoxicações e toxinfecções alimentares $^{[11]}$. Os principais agentes etiológicos identificados nos surtos de DTA no Brasil são as bactérias: Escherichia coli, Salmonella entérica, Staphylococcus aureus e Bacillus cereus $^{[12]}$.

O microrganismo E. coli é um bacilo Gram-negativo não esporulado, que habita normalmente $\mathrm{o}$ intestino da maioria dos animais, incluindo seres humano e pode indicar contaminação fecal devido às falhas higiênicas na manipulação de alimentos e ao uso de água contaminada ${ }^{[13]}$. A S. entérica é um bacilo Gram-negativo e os alimentos mais implicados na sua transmissão são à base de ovos e/ou gemas cruas (maioneses caseiras) e carnes de aves mal cozidas ou contaminadas de forma cruzada após cocção por meio de utensílios contaminados $^{[12,14]}$. Os S. aureus são cocos Gram-positivos, que produzem enterotoxinas e tem sido frequentemente envolvido em surtos de toxinfecções alimentar, estando muito associado à manipulação inadequada dos alimentos, uma vez que, são comumente encontrados na pele, mucosas do trato respiratório superior e intestino de humanos ${ }^{[14]}$. Os B. cereus são bacilos Gram-positivos, produtores de esporos e toxinas, os alimentos implicados em DTA são os pratos à base de cereais, principalmente $\mathrm{o}$ arroz, a proliferação desta bactéria e a liberação de toxinas, estão associadas às falhas na conservação dos alimentos expostos por tempos e temperaturas inadequadas ${ }^{[12]}$. 
Diante do exposto, o objetivo desta pesquisa foi avaliar o efeito antimicrobiano e sinergístico de óleos essenciais sobre bactérias contaminantes de alimentos, como um potencial substituto natural de aditivos químicos em alimento.

\section{MATERIAL E MÉTODOS}

\section{1. Óleos essenciais}

Os óleos essenciais de cravo e orégano foram adquiridos na forma pronta, em empresa de óleos essenciais (Ponta Grossa, Paraná, Brasil), sendo obtido por extração por arraste de vapor. O óleo essencial de cravo da marca QUINARÍ ${ }^{\circledR}$ (ANVISA $\mathrm{n}^{\circ}$ 25351.183090/ 2017-50) foi extraído dos botões e apresenta como principal constituinte o eugenol. O óleo essencial de orégano da marca QUINARÍ ${ }^{\circledR}$ (ANVISA $\mathrm{n}^{\circ}$ 25351.183189/ 2017-11) foi extraído das folhas e apresenta como principal componente o carvacrol.

\subsection{Bactérias}

Os microrganismos testes cepas utilizados foram: Escherichia coli (ATCC 8739), Salmonella entérica (ATCC 6017), Staphylococcus aureus (ATCC 6538) e Bacillus cereus (ATCC 11778), adquiridas da empresa Interlab (Distribuidora de Produtos Científicos Ltda, SP, Brasil) e padronizadas e distribuídas pelo American Type Cell Collectin (ATCC, Manassas, VA, USA). Durante o armazenamento, as cepas liofilizadas foram mantidas refrigeradas $\left(4^{\circ} \mathrm{C}\right)$. Para ativação, os microrganismos foram reidratados em solução salina estéril e cultivados em caldo triptona de soja (TSB) (HIMEDIA, Índia), seguida da incubação a $36 \pm 1{ }^{\circ} \mathrm{C}$ por 24 horas em estufa bacteriológica (FANEM, Brasil). O isolamento das colônias foi feito em placas de Petri contendo meio de cultura específico para cada microorganismo: E. coli em ágar macconkey
(HIMEDIA, Índia), S.entérica em ágar Salmonella-Shigella (SS) (HIMEDIA, Índia), S.aureus em ágar manitol salgado (HIMEDIA, Índia) e B.cereus em ágar manitol gema de ovo polimixina (MYP) (HIMEDIA, Índia), e posteriormente, incubadas nas mesmas condições anteriores. Para o preparo da suspensão bacteriana foram transferidas de três a cinco colônias de cada microrganismo para os tubos de ensaio contendo solução salina estéril $(\mathrm{NaCl}$ a $0,85 \% \mathrm{p} / \mathrm{v})$, ajustando-se a turbidez do inoculo com o padrão de 0,5 da escala de McFarland (aproximadamente 1,5 x 108 $\mathrm{UFC} / \mathrm{mL}$ ), usando um turbidímetro (DENSIMAT-BIOMERIEUX, França).

\subsection{Avaliação antimicrobiana dos óleos essenciais}

A ação antimicrobiana dos óleos essenciais foi avaliada por meio da técnica de difusão em disco, descrito por Kirby-Bauer, segundo as recomendações do "National Comitee for Clinical Laboratory Standard",[15]. O meio de cultura foi preparado em placas de Petri estéreis, sendo adicionados em cada placa $25 \mathrm{~mL}$ de Ágar Mueller-Hinton (MERCK, Alemanha). Após a solidificação do meio de cultura, com o auxílio de swab estéril, as suspensões padronizadas a 0,5 da escala McFarland foram semeadas nas superfícies das placas por meio de esfregaço uniforme, deixoas secar (3 min) e então, foram depositados os discos de papel de filtro (6 $\mathrm{mm}$ de diâmetro), impregnados nos óleos essenciais. Os óleos puros foram impregnados nos discos em três diferentes concentrações $(10,20$ e $30 \mu \mathrm{L})$, os valores mínimo, intermediário e máximo foram baseados nas concentrações comumente utilizadas na literatura para óleos essenciais $^{[16,17,18,19,20,21]}$. As combinações binárias dos óleos foram impregnadas nos discos, de forma que, as somas desses óleos permanecessem nas mesmas concentrações dos óleos puros (10, 20 e $30 \mu \mathrm{L})$, assim, para cada óleo foram utilizadas quatro diferentes concentrações $(5,10,15$ e $20 \mu \mathrm{L})$. Para todas as 
bactérias testadas, foi depositado um disco de controle negativo somente com a solução salina estéril (branco) e um disco de controle positivo, contendo $30 \mu \mathrm{g}$ do antibiótico clorafenicol. Em seguida, o sistema foi incubado a $36 \pm 1{ }^{\circ} \mathrm{C}$ por 24 horas em estufa bacteriológica (FANEM, Brasil), e posteriormente, realizada a medição do diâmetro dos halos de inibição $(\mathrm{mm})$ por meio de um paquímetro. Foi considerado como possuidor de atividade antimicrobiana $\mathrm{O}$ produto que apresentou a formação de um halo de inibição igual ou superior a $10 \mathrm{~mm}$ de diâmetro $^{[22]}$. Os testes foram realizados em triplicata.

\subsection{Análise estatística dos dados}

Os resultados das análises foram avaliados por meio da estatística descritiva (média e desvio padrão), com o auxílio do software Microsoft Office Excel 2007 e para verificar a existência de diferença entre os resultados, foi realizada à análise de variância (ANOVA) e as médias comparadas pelo teste de Tukey a $5 \%$ de significância $(p \leq 0,05)$, por meio do software Statistica 7.0 (StatSoft, Tulsa, USA).

Tabela 1: Crescimento microbiano de cepas de E. coli, S. entérica, S. aureus e B. cereus em diferentes concentrações dos óleos essenciais de cravo e orégano.

\begin{tabular}{llllll}
\hline \multirow{2}{*}{ OE } & \multirow{2}{*}{$(\boldsymbol{\mu} \mathbf{L})$} & \multicolumn{4}{c}{ Diâmetro do halo de inibição $(\mathbf{m m})$} \\
\cline { 3 - 6 } & 10 & $0^{\mathrm{Aa}}$ coli & $\boldsymbol{S}$. entérica & $\boldsymbol{S}$. aureus & B. cereus \\
\hline \multirow{2}{*}{ OEC } & 20 & $12,67 \pm 1,15^{\mathrm{Bb}}$ & $9,33 \pm 0,58^{\mathrm{Ba}}$ & $17,67 \pm 1,15^{\mathrm{Bc}}$ & $14,67 \pm 0,58^{\mathrm{Bb}}$ \\
& 30 & $17,00 \pm 1,00^{\mathrm{Cb}}$ & $14,00 \pm 0,58^{\mathrm{Ca}}$ & $22,00 \pm 1,00^{\mathrm{Cc}}$ & $19,00 \pm 1,00^{\mathrm{Cb}}$ \\
\hline \multirow{2}{*}{ OEO } & 10 & $0^{\mathrm{Aa}}$ & $0^{\mathrm{Aa}}$ & $15,00 \pm 1,00^{\mathrm{Ac}}$ & $12,33 \pm 0,58^{\mathrm{Ab}}$ \\
& 20 & $15,00 \pm 1,00^{\mathrm{Bb}}$ & $10,67 \pm 1,15^{\mathrm{Ba}}$ & $23,67 \pm 1,15^{\mathrm{Bd}}$ & $18,67 \pm 0,58^{\mathrm{Bc}}$ \\
& 30 & $22,67 \pm 0,58^{\mathrm{Cb}}$ & $18,33 \pm 0,58^{\mathrm{Ca}}$ & $27,67 \pm 0,58^{\mathrm{Cd}}$ & $25,00 \pm 1,00^{\mathrm{Cc}}$
\end{tabular}

OE: óleo essencial; OEC: óleo essencial de cravo; OEO: óleo essencial de orégano; C: concentração $(\mu \mathrm{L})$; Médias seguidas da mesma letra maiúscula na mesma coluna ou minúscula na mesma linha, não diferem entre si, pelo teste de Tukey a $5 \%$ de significânia $(p \leq 0,05)$.

\section{RESULTADOS E DISCUSSÃO}

A Tabela 1 apresenta a atividade antimicrobiana (halo de inibição do crescimento em $\mathrm{mm}$ ) dos óleos essenciais de Eugenia caryophyllata (cravo) e Origanum vulgare (orégano) sobre as bactérias contaminantes dos alimentos.
Observa-se na Tabela 1 que o aumento da concentração de óleo essencial provocou um aumento significativo no efeito antimicrobiano $(p \leq 0,05)$. As bactérias Gram-negativas (E. coli e $\mathrm{S}$. entérica) se mostraram mais resistente, inclusive sem inibição do halo em $10 \mu \mathrm{L}$ dos óleos puros. As bactérias Gram-positivas (S. aureus e B. cereus) foram mais sensíveis à inibição por esses óleos, apresentando halo de inibição em todas as concentrações estudadas. As bactérias S. aureus foram mais susceptíveis 
aos óleos, apresentando halos de inibição significativamente maiores $(p \leq 0,05)$, inclusive com a formação de halos de inibição de até 27,67 $\mathrm{mm}$ de diâmetro em $30 \mu \mathrm{L}$ do óleo de orégano. Enquanto, a S. entérica foi a mais resistente, com halos de inibição significativamente menores $(p \leq 0,05)$, quando comparado às demais cepas.

Estudos sugerem que as bactérias Gram-positivas são mais susceptíveis aos óleos essenciais, do que as Gram-negativas ${ }^{[3,23,24]}$. Isto ocorre provavelmente devido a complexidade estrutural da parede celular das Gram-negativas que apresentam uma membrana externa composta por lipopolissacarídeos, responsável por envolver a parede celular e proporcionar uma maior resistência, a qual restringe a difusão e dificulta a disseminação e acúmulo do óleo essencial na célula bacteriana ${ }^{[3,4,7,9,25]}$. Acredita-se que os óleos essenciais exercem efeitos como: a perturbação da membrana citoplasmática pela interferência na bicamada fosfolipídica da parede celular; aumento da permeabilidade e perda dos constituintes celulares; e alteração de uma variedade de sistemas enzimáticos, incluindo aqueles envolvidos na produção de energia celular e síntese de componentes estruturais ou por inativação e destruição do material genético, resultando em perda do controle quimiosmótico da célula afetada, levando a morte bacteriana ${ }^{[4,16]}$. De acordo com Silva et al. ${ }^{[2]}$, o óleo de coentro (Coriandrum sativum L.) afetou a integridade da membrana celular da maioria das bactérias estudadas e como resultado do aumento da permeabilidade da membrana, todas as outras funções celulares, como o potencial da membrana em impedir o acumulo de substâncias nocivas, atividade respiratória e o mecanismo de resistência devido a menor atividade da bomba de efluxo, foram comprometidas. Conforme Cui et al. ${ }^{[27]}$, o óleo essencial de Salvia sclarea além do aumento da permeabilidade da membrana celular, levou à liberação de material citoplasmático do interior da célula, ocorrendo o extravassamento de substâncias macromoleculares tal como o DNA e a liberação de ATP, o que promoveu a perda de energia das células bacterianas estudadas. $\mathrm{O}$ mesmo foi observado por Zhang et al. ${ }^{[28]}$, ao estudarem o mecanismo de ação do óleo essencial de pimenta preta contra E. coli; os autores constataram a ruptura tanto da membrana externa da célula quanto do citoplasma, com o extravazamento não só de materiais de DNA e ATP, mas também de proteínas e eletrólitos (íons de potássio e fosfato), o que levou a alterações na atividade enzimática, desordem no equilíbrio hidroeletrolítico e na síntese de macromoléculas (DNA， RNA， proteínas e polissacarídeos), resultando na inibição do crescimento, decomposição e morte bacteriana.

Os resultados obtidos no presente estudo indicam que óleo essencial de orégano (carvacrol: $73,9 \%$, timol: $13,5 \%, \gamma$-terpineno: 8,9\%, p-cimeno: $2,7 \%$ ) obteve um espectro de ação maior em relação ao cravo (eugenol: $71,4 \%$, acetato de eugenila: $11,3 \%$, transcariofleno: $10,2 \%$, e $\alpha$-humuleno: 6,1\%). Santos et al. ${ }^{[25]}$, ao estudarem a atividade antibacteriana de óleos essenciais, também observaram que o orégano (carvacrol: 80\%) comparado ao cravo (eugenol: 90\%,) apresentou os maiores halos de inibição bacteriana (S. aureus e E.coli). Porém, Pereira et al. ${ }^{[29]}$ ao avaliarem o efeito inibitório dos óleos essenciais sobre bactérias (S. aureus e E.coli), atribuíram os melhores resultados de inibição ao cravo (eugenol: 86,3\%, transcariofileno: $8,2 \%$, acetato de eugenila: $3,6 \%$ e $\alpha-$ humuleno: $0,8 \%$ ), do que ao orégano (terpen-4ol: $26,3 \%, \beta$-cimeno: $16,6 \%, \gamma$-terpineno: $16 \%$, carvacrol: $7,2 \%$, linalol: $12,3 \%, \alpha$-terpineno: 6,9\%, p-cimeno: 4,6\%, $\alpha$-terpineol: $3,8 \%$, mirceno: $\quad 2,7 \%, \quad \beta$-felandreno: $\quad 2,3 \%$, terpinoleno: $1,8 \%$, acetato de linalila: $1,7 \%$, carvacrol metil éter: $1,6 \%$, trans-cariofileno: $1,3 \%, \alpha$-felandreno: $1,1 \%$, timol metil éter: $0,8 \%$ e $\alpha$-pineno: $0,7 \%$ ). Portanto, a ação antibacteriana dos óleos essenciais está diretamente relacionada com a sua composição química, que podem variar dependendo de 
fatores como: região de cultivo, parte da planta utilizada, preparo da matéria prima (seca ou in natura) e metodologia de extração $\mathrm{O}^{[9,30,31]}$. Estes fatores justificam as variações observadas entre este trabalho e os estudos citados.

Segundo Silva et al. ${ }^{[32]}$, a atividade antimicrobiana não se deve somente à presença dos compostos majoritários dos óleos essenciais, mas da presença de outros componentes em menores concentrações que podem promover interações sinérgicas, por exemplo, o p-cimeno não tem efeito antibacteriano se usado sozinho, mas quando combinado com carvacrol, facilita o transporte do carvacrol por meio da membrana citoplasmática para o interior da célula bacteriana. Conforme os autores, o OEO com menor teor de carvacrol (61,7\%), mas presença de $\mathrm{p}$-cimeno e também de $\gamma$-terpineno, apresentou maiores halos de inibição a partir da concentração 0,2\%. Enquanto, o OEO com elevado teor de carvacrol (93,4\%), mas sem a presença de $\mathrm{p}$-cimeno ou $\gamma$-terpineno, apresentou halos de inibição menores.
A Tabela 2 apresenta os dados do efeito sinergístico de diferentes concentrações da mistura dos óleos essenciais de Eugenia caryophyllata (cravo) e Origanum vulgare (orégano) sobre a formação do halo de inibição (mm) do crescimento bacteriano.

A partir da Tabela 2, verifica-se que as misturas binárias de $\mathrm{OE}$ utilizadas na mesma proporção não apresentaram sinergismo, inclusive sem crescimento do halo de inibição para as bactérias Gram-negativas, tanto a E. coli, como a S. entérica não apresentaram diferença significativa entre si $(p \leq 0,05)$, sendo as bactérias mais resistentes, com halos de inibição significativamente menores $(p \leq 0,05)$, quando comparado às demais cepas. Enquanto, as misturas em que foram utilizadas proporções diferentes de OE, principalmente as que continham maior concentração de $\mathrm{OEO}$ e menor de OEC apresentaram sinergismo, indicando halos de inibição significativamente maiores $(p \leq 0,05)$, inclusive com a formação de

Tabela 2: Crescimento microbiano de cepas de E. coli, S. entérica, S. aureus e B. cereus em diferentes combinações dos óleos essenciais de cravo e orégano.

\begin{tabular}{llllll}
\hline \multirow{2}{*}{ OEC $(\mu \mathrm{L})$} & OEO $(\mu \mathrm{L})$ & \multicolumn{4}{c}{ Diâmetro do halo de inibição $(\mathbf{m m})$} \\
\cline { 3 - 6 } & & $\mathbf{E}$. coli & S. entérica & $\boldsymbol{S}$. aureus & $\boldsymbol{B}$. cereus \\
\hline 5 & 5 & $0^{\mathrm{Aa}}$ & $0^{\mathrm{Aa}}$ & $0^{\mathrm{Aa}}$ & $0^{\mathrm{Aa}}$ \\
5 & 15 & $14,33 \pm 0,58^{\mathrm{Ca}}$ & $13,33 \pm 1,15^{\mathrm{Ca}}$ & $23,00 \pm 1,00^{\mathrm{Dc}}$ & $20,00 \pm 1,00^{\mathrm{Db}}$ \\
15 & 5 & $10,00 \pm 1,00^{\mathrm{Ba}}$ & $9,00 \pm 1,00^{\mathrm{Ba}}$ & $18,33 \pm 0,58^{\mathrm{Cc}}$ & $15,00 \pm 1,00^{\mathrm{Cb}}$ \\
10 & 10 & $0^{\mathrm{Aa}}$ & $0^{\mathrm{Aa}}$ & $0^{\mathrm{Aa}}$ & $0^{\mathrm{Aa}}$ \\
10 & 20 & $17,67 \pm 0,58^{\mathrm{Da}}$ & $16,33 \pm 1,15^{\mathrm{Da}}$ & $30,00 \pm 0,00^{\mathrm{Ec}}$ & $25,67 \pm 0,58^{\mathrm{Eb}}$ \\
20 & 10 & $11,67 \pm 0,58^{\mathrm{Ba}}$ & $10,00 \pm 0,00^{\mathrm{Ba}}$ & $19,00 \pm 1,00^{\mathrm{Cc}}$ & $16,33 \pm 0,58^{\mathrm{Cb}}$ \\
15 & 15 & $0^{\mathrm{Aa}}$ & $0^{\mathrm{Aa}}$ & $9,67 \pm 0,58^{\mathrm{Bc}}$ & $7,33 \pm 1,00^{\mathrm{Bb}}$
\end{tabular}

OEC: óleo essencial de cravo; OEO: óleo essencial de orégano; Médias seguidas da mesma letra maiúscula na mesma coluna ou minúscula na mesma linha, não diferem entre si, pelo teste de Tukey a $5 \%$ de significância $(p \leq 0,05)$. 
halos de inibição de até $30 \mathrm{~mm}$ de diâmetro em $20 \mu \mathrm{L}$ do OEO e $10 \mu \mathrm{L}$ do OEC para a bactéria $S$. aureus que foi novamente a mais susceptível as misturas dos óleos.

Acredita-se que quando estes óleos são misturados na mesma proporção um acabe interferindo no potencial do outro, devido à destruição de algum componente que em menor concentração auxiliava no sinergismo individual do óleo. Barbosa et al. ${ }^{[3]}$ constataram que ao misturar óleos essenciais em iguais proporções (1:1), as porcentagem dos compostos ativos diminuíram, inclusive com o desparecimento de alguns compostos presentes em menores concentração no óleo individual. Pereira et al. ${ }^{[29]}$ e Oliveira et al. ${ }^{[6]}$, ao misturar os óleos essenciais nas mesmas proporções, também não observaram efeito sinergístico. Porém, quando a mistura ocorre em proporções diferentes, provavelmente, o óleo adicionado em menor proporção não prejudique a composição química do outro óleo, que combinados adequadamente conseguem promover o sinergismo entre os dois e potencializar o seu efeito antibacteriano contra os patógenos estudados (E. coli, S. entérica, S. aureus e B. cereus). García-García et al. ${ }^{[33]}$, ao estudar a atividade bactericida das misturas binárias e terciárias do carvacrol, timol e eugenol, obtiveram melhores resultados com as combinações em diferentes proporções, evidenciando atividade sinérgica entre estes compostos. Rapper et al. ${ }^{[34]}$, ao avaliar diferentes óleos essenciais, também constataram efeito sinergístico mais favorável, quando utilizaram maiores proporções do óleo L. angustifolia combinados aos outros óleo, sugerindo que a presença deste óleo desempenhava um papel maior na sinergia observada.

Os resultados das misturas binárias de óleos essenciais indicam que seu efeito depende não apenas dos constituintes químicos presentes nos óleos, mas das diferentes proporções em que eles se encontram em cada mistura; bem como da susceptibilidade do organismo alvo.

\section{CONCLUSÃO}

O óleo essencial de orégano apresentou maior potencial inibidor que o óleo de cravo frente às bactérias estudadas. As bactérias Gram-positivas (S. aureus e B. cereus) foram mais susceptíveis aos óleos essenciais, comparadas as Gram-negativas (E. coli e S. entérica). $\mathrm{O}$ desempenho satisfatório para as bactérias Gram-negativas foi alcançado com as maiores concentrações dos óleos estudados (20 e $30 \mu \mathrm{L})$. As misturas binárias desses óleos na mesma proporção não apresentaram sinergismo. Entretanto, as misturas em diferentes proporções, principalmente com as maiores concentrações de orégano e menores de cravo promoveram interações sinérgicas entre os óleos e potencializou o seu efeito antibacteriano. Assim, conclui-se que os óleos estudados constituem uma excelente alternativa de conservação, possibilitando a substituição de aditivos químicos, uma vez que, estes produtos naturais possuem um potente e amplo espectro de ação antibacteriana.

\section{AGRADECIMENTOS}

Os autores agradecem ao Laboratório de Microbiologia (PPGCF-UFPa) pelo suporte laboratorial para a execução da parte experimental.

\section{REFERÊNCIAS}

[1] Sarto, MPM, Zanusso Junior, G. Atividade antimicrobiana de óleos essenciais. Revista UNINGÁ Review. 2014; 20(1):98-102.

[2] Santos, GG, Trindade, RC, Alves, JAB, Santos, PO, Alves, PB, Blank, AF, Carvalho, LM, Aquino, LCL. Atividade antimicrobiana 
dos óleos essenciais de erva-cidreira e manjericão frente a bactérias de carnes bovinas. Alimentos e Nutrição Araraquara. 2010; 21(4):529-535.

[3] Barbosa, LN, Probst, IS, Andrade, BFMT, Alves, FCB, Albano M, Cunha, MLRS, Doyama, JT, Rall, VLM, Júnior, AF. In vitro antibacterial and chemical properties of essential oils including native plants from Brazil against pathogenic and resistant bacteria. Journal of Oleo Science. 2015; 64(3):289-298.

[4] Carvalho, NB, Santos, ANS, Pinheiro, EO, Leal, LRA. Potencial antioxidante e antimicrobiano de óleos essenciais de especiarias: uma revisão. Higiene Alimentar. 2016; 30:12-20.

[5] Tarcitano, LAC, Mesquita, EFM. Ação dos condimentos alimentares in natura sobre a microbiota patógena durante o processamento, preparo e/ou consumo do pescado: uma revisão sistemática de literatura. Arquivos de Ciência do Mar. 2017; 50(1):141-162.

[6] Oliveira, MMM, Brugnera, DF, Cardoso, MG, Guimarães, LGL, Piccoli, RH. Rendimento, composição química e atividade antilisterial de óleos essenciais de espécies de Cymbopogon. Revista Brasileira de Plantas Medicinais. 2011; 13(1):8-16.

[7] Santos, CHS, Piccoli, RH, Tebaldi, VMR. Atividade antimicrobiana de óleos essenciais e compostos isolados frente aos agentes patogênicos de origem clínica e alimentar. Revista do Instituto Adolfo Lutz. 2017; 76:1-8.

[8] Affonso, RS, Rennó, MN, Slana, GBCA, França, TCC. Aspectos químicos e biológicos do óleo essencial de cravo da Índia. Revista Virtual de Química. 2012; 4(2):146-161.

[9] Guimarães, CC, Ferreira, TC, Oliveira, RCF, Simioni, PU, Ugrinovich, LA. Atividade antimicrobiana in vitro do extrato aquoso e do óleo essencial do alecrim (Rosmarinus officinalis L.) e do cravo-da-índia (Caryophyllus aromaticus L.) frente a cepas de Staphylococcus aureus e Escherichia coli. Revista Brasileira de Biociência. 2017; 15(2):83-89.

[10] Romero, AL, Romero, RB, Silva, EL, Diniz, SPSS, Oliveira, RR, Vida, J B. Composição química e atividade do óleo essencial de Origanum vulgare sobre fungos fitopatogênicos. UNOPAR Cientifica Ciências Biológicas e da Saúde. 2012; 14(4):231-235.

[11] Oliveira, JJ, Rezende, CSM, Oliveira, AP, Moreira, NM, Freitas, FA. Surtos alimentares de origem bacteriana. Enciclopédia Biosfera. 2013; 9(17):2416-2433.

[12] Nunes, SM, Cergole-Novella, MC, Tiba, MR, Zanon, CA, Bento, ISS, Paschualinoto, AL, Thomaz, I, Silva, AA, Walendy, CH. Surto de doença transmitida por alimentos nos municípios de Mauá e Ribeirão Pires - SP. Higiene Alimentar. 2017; 31:92-102.

[13] Lima, DS, Lima, JC, Calvacanti, RMCB, Santos, BHC, Lima, IO. Estudo da atividade antibacteriana dos monoterpenos timol e carvacrol contra cepas de Escherichia coli produtoras de $\beta$-lactamases de amplo espectro. Revista Pan-Amazônica de Saúde. 2017; 8(1):17-21.

[14] Oliveira, ABA, Paula, CMD, Capalonga, R, Cardoso, MRI.; Tondo, EC. Doenças transmitidas por alimentos, principais agentes etiológicos e aspectos gerais: uma revisão. Revista HCPA. 2010; 30(3):279-285.

[15] National Committee For Clinical Laboratory Standard (NCCLS). Performance Standards for Antimicrobial Disk Susceptibility Tests: Approved Standard - Eighth Edition. NCCLS document M2-A8. 2003; 23(1):1-58.

[16] Silvestri, JDF, ParouL, N, Czyewski, E, Lerin, L, Rotava, I, Cansian, RL, Mossi, A, 
Toniazzo, G, Oliveira, D, Treichel, H. Perfil da composição química e atividades antibacteriana e antioxidante do óleo essencial do cravo-daíndia (Eugenia caryophyllata Thunb.). Revista Ceres. 2010; 57(5):589-594.

[17] Veloso, RA, Castro, HG, Cardoso, DP, Santos, GR, Barbosa, LCA, Silva, KP. Composição e fungitoxicidade do óleo essencial de capim citronela em função da adubação orgânica. Pesquisa Agropecuária Brasileira. 2012; 47(12):1707-1713.

[18] Steffen, RB, Antoniolli, ZI, Steffen, GPK, Jacques, RJS, Santos, ML, Godoy, HT, Bogusz Júnior, S. Óleo essencial de eucalipto como bioestimulador do crescimento de fungos ectomicorrízicos in vitro. Ciência Florestal. 2013; 23(2):403-414.

[19] Cruz, TP, Alves, FR, Mendonça, RF, Costa, AV, Jesus Junior, WC, Pinheiro, PF, Marins, AK. Atividade fungicida do óleo essencial de Cymbopogon winterianus jowit (citronela) contra Fusarium solani. Bioscience Journal. 2015; 31(1):1-8.

[20] Souza, LP, Zago, HB, Costa, AV, Stinguel, $\mathrm{P}$, Valbon, WR. Composição química e atividade acaricida do óleo essencial de erva-desanta-maria sobre o ácaro-rajado. Revista Caatinga. 2015; 28(1):160-166.

[21] Falcão, L, Roman, SS, Zakrzevski, SBB, Pereira, AAM; Paroul, N, Cansian, RL. Ação antimicrobiana do óleo essencial de folhas de Casearia sylvestris swartz. Perspectiva. 2017; 41(153):115-123.

[22] Wong-Leung, YL. Antibacterial activities of some Hong Kong plants used in Chinese medicine. Fitoterapia. 1988; 69(1):11-16.

[23] Sivasothy, Y, Chong, WK, Hamid, A, Eldeen, IM, Sulaiman, SF, Awang, K. Essential Oils of Zingiber officinale var. Rubrum
Theilade and Their Antibacterial Activities. Food Chemistry. 2011; 124:514-517.

[24] Araújo, RS, Serra, JL, Nascimento, AR. Composição química e susceptibilidade do óleo essencial de óregano (Origanum vulgare L., família Lamiaceae) frente às cepas de Escherichia coli, Staphylococcus aureus e Salmonella choleraesuis. Boletim do Centro de Pesquisa de Processamento de Alimentos. 2015; 33(74 1):73-78.

[25] Santos, JC, Carvalho Filho, CD, Barros, TF, Guimarães, AG. Atividade antimicrobiana in vitro dos óleos essenciais de orégano, alho, cravo e limão sobre bactérias patogênicas isoladas de vôngole. Semina: Ciências Agrárias. 2011; 32(4):1557-1564.

[26] Cui, H, Zhang, X, Zhou, H, Zhao, C, Lin, L. Antimicrobial activity and mechanisms of Salvia sclarea essential oil. Botanical Studies. 2015; 56(16):2-8.

[27] Silva, F, Ferreira, S, Queiroz, JA, Domingues, FC. Coriander (Coriandrum sativum L.) essential oil: its antibacterial activity and mode of action evaluated by flow cytometry. Journal of Medical Microbiology. 2011; 60:1479-1486.

[28] Zhang, J, Ye, K, Zhang, X, Pan, D, Sun, Y, Cao, J. Antibacterial Activity and Mechanism of Action of Black Pepper Essential Oil on Meat-Borne Escherichia coli. Frontiers in Microbiology. 2017; 7:1-10.

[29] Pereira, AA, Cardoso, MG, Abreu, LRA, Morais, AR, Guimarães, LGL, Salgado, APSP. Caracterização química e efeito inibitório de óleos essenciais sobre o crescimento de Staphylococcus aureus e Escherichia coli. Ciência e Agrotecnologia. 2008; 32(3):887-893.

[30] Ribeiro, DS, Melo, DB, Guimaraes, AG, Velozo, ES. Avaliação do óleo essencial de alecrim (Rosmarinus officinalis L.) como 
modulador da resistência bacteriana. Semina: Ciências Agrárias. 2012; 33(2):687-696.

[31] Valeriano, C, Piccoli, RH, Cardoso, MG, Alves, E. Atividade antimicrobiana de óleos essenciais em bactérias patogênicas de origem alimentar. Revista brasileira de plantas medicinais. 2012; 14(1):57-67.

[32] Silva, JPL, Duarte-Almeida, JM, Perez, DV, Franco, BDGM. Óleo essencial de orégano: interferência da composição química na atividade frente a Salmonella Enteritidis. Ciência e Tecnologia de Alimentos. 2010; 30:136-141.

[33] García-García, R, López-Malo, A, Palou, E. Bactericidal action of binary and ternary mixtures of carvacrol, thymol, and eugenol against Listeria innocua. Journal of Food Science. 2011; 76(2):95-100.

[34] Rapper, S, Kamatou, GPP, Viljoen, AM, Vuuren, SFV. The in vitro antimicrobial activity of Lavandula angustifolia essential oil in combination with other aroma-Therapeutic Oils. Evidence-Based Complementary and Alternative Medicine. 2013; 2013:1-10. 